\title{
ACE inhibitörü /ARB, Beta-bloker ve MRA ile stabil seyreden NYHA II kalp yetersizliği olgularında sakubitril/valsartan'a geçilmeli mi?
}

\author{
Dr. Ahmet Genç
}

Sağlık Bilimleri Üniversitesi, Antalya Eğitim ve Araştırma Hastanesi, Kardiyoloji Kliniği, Antalya

Kalp yetersizliği (KY) kalbin dokuların metabolik ihtiyacını karşılayacak kan akımını sağlayamadığı klinik bir sendromdur ve birçok kardiyovasküler hastalığın sonucu olarak karşımıza çıkar. Hastaların büyük kısmında yavaş ilerleyen kronik KY olarak görülmektedir. Klinik seyrinde sıklıkla semptom ve bulguların akut kötüleşmesi ile ortaya çıkan akut dekompanse KY (ADKY) tablosu gelişir. Sistolik fonksiyona göre KY; düşük ejeksiyon fraksiyonlu KY (DEFKY), s1nırda ejeksiyon fraksiyonlu KY (SEFKY), korunmuş ejeksiyon fraksiyonlu KY (KEFKY) olarak üç gruba ayrilmaktadır. $^{[1]}$

Avrupa Kardiyoloji Derneği (ESC) KY kılavuzuna göre kronik KY olan hastada 'stabil' olma durumu semptomların hafif veya yokluğu ile en az bir aydır bulgularda değişiklik olmaması olarak tarif edilmektedir. ${ }^{[1]}$ Buna rağmen KY sebepli hastaneye yatışların ve ölümlerin büyük çoğunluğu göreceli olarak stabil seyreden ancak nörohormonal dengesizlik ve endotelyal disfonksiyonun sebep olduğu semptomsuz progresyonun görüldüğü NYHA sinıf II ve III hasta gruplarında görülmektedir. Bu yüzden bir klinisyen 'stabil' görünen semptomsuzluk veya hafif semptomatik oluşu iyi prognoz garantisi olarak görmemelidir. Kontrol vizitinde semptom ve bulguları olmayan ama daha önce semptomatik olmuş bir hasta (ACC/ AHA Evre C) ciddi mortalite riskine sahiptir (5 y1llik mortalite \%22), bu durum semptomatik hastaya göre düşük risk içerse de (5 yıllık mortalite \%40) hiç semptomatik olmamış bir hastaya göre (ACC/AHA evre B) ciddi derecede yüksek riske sahiptir (5 yıllık mortalite \%4). ${ }^{[2]}$ Ani kardiyak ölümler 'stabil' görünen hafif semptomlu/semptomsuz hastalarda daha sıklıkla görülmektedir. ${ }^{[3]}$ Klinik olarak 'stabil' görünen birçok KY hastasında altta yatan miyosit hasarını gösteren kardiyak troponin T yüksekliği saptanmıştır. ${ }^{[4]} \mathrm{Bu}$ yüzden stabil KY hastası diye bir kavramın gerçekte olmadığ 1 ve KY'nin hemen hemen daima prog- resif seyrettiği akıldan çıkarılmamalıdır. KY hastalarının büyük çoğunluğunu oluşturan NYHA II ve III hastalarda hastalığın progresyonunu azami derecede azaltacak kanıta dayalı bütün tedaviler kılavuzların önerileri doğrultusunda kullanılmalıdır ve hedeflenen dozlara ulaşmak için gayret gösterilmelidir.

DEFKY tıbbi tedavisinin temelini bütün kılavuzlarca da önerilen nörohormonal blokerler oluşturmaktadır. ${ }^{[1,5]}$ İlk basamak nörohormonal blokerler renin anjiotensin ve aldesteron sistemini bloke eden ACEİ/ ARB, MRA ile adrenerjik blokaj sağlayan beta-bloker ajanlardan oluşmaktadır. Yeni kuşak nörohormonal bloker olarak 2014 yılında PARADIGMHF çalışması ile etkinliği kanıtlanan anjiotensin reseptör-neprilisin inhibitörü (ARNI) sakubitril/valsartandır (S/V). ${ }^{[6]}$ PARADIGM-HF çalışmasında S/V bir ACEİ olan enalaprile karşı etkinlik ve güvenlik açısından karşılaştırılmıştır. ${ }^{[6]}$ Çalışmada kullanılan ortanca enalapril dozu (18.9 mg/gün), enalaprille yapılan çalışmalarda ulaşılan en yüksek düzeydir. ${ }^{[6]}$ Bu randomize çift kör faz 3 çalışmaya DEFKY olan 8442 hasta dahil edilmiştir ve hastaların yaklaşık \%72'si 'stabil' olarak değerlendirilen NYHA sınıf II ve \%23.1'i sınıf III fonksiyonel kapasiteye sahipti, NYHA I ve IV sınıf hasta sayısı çok sınırlı sayıdaydı ve yeterli düzeyde standart DEFKY (ACEİ/ARB, beta-bloker, MRA) tedavisi almaktayd $1 .{ }^{[6]}$ Çalışmanın 27 aylık median takip süresi sonunda kardiyovasküler ölüm veya ilk defa KY nedenli hastaneye yatış bileşik sonlanım noktasında \%20 (HR: 0.80; \%95 GA 0.730.87; p<0.001), kardiyovasüler ölümde \%20 (HR: $0.80 ; \% 95$ GA $0.71-0.89 ; \mathrm{p}<0.001)$, tüm sebeplere bağlı ölümde \%16 (HR: 0.84; \%95 GA 0.76-0.93; $\mathrm{p}<0.001)$ azalma sağlamıştır. ${ }^{[6]} \mathrm{S} / \mathrm{V}$, ani kardiyak ölümü de enalaprile göre anlamlı azaltmıştır (HR: 0.80; $\% 95$ GA 0.68-0.94; $p=0.008) .^{[7]}$

PARADIGM-HF çalışmasının kontrol grubunun dörtte birinde kılavuza dayalı tedavi almalarına ră̆-

Yazışma adresi: Dr. Ahmet Genç. Sağlık Bilimleri Üniversitesi, Antalya Eğitim ve Araştırma Hastanesi, 


\begin{tabular}{|c|c|c|}
\hline & $\mathrm{ACC} / \mathrm{AHA}$ & ESC \\
\hline Öneri düzeyi & Sınıf IB & Sinıf IB \\
\hline NYHA sınıf önerisi & NYHA II-III & NYHA II-IV \\
\hline MRA kullanma şartı & Yok & Var \\
\hline ACEI/ARB doz şartı & $\begin{array}{c}\text { Tolere edilen } \\
\text { doz }\end{array}$ & $\begin{array}{c}\text { 2X10 mg Enalaprile } \\
\text { eş değer doz }\end{array}$ \\
\hline BNP/NT-proBNP şartı* & Yok & Var \\
\hline EF şartı & $<\% 40$ & $\leq \% 35$ \\
\hline
\end{tabular}

*: BNP $\geq 150 \mathrm{pg} / \mathrm{ml}$ veya NT-proBNP $\geq 600 \mathrm{pg} / \mathrm{ml}$ veya son bir yıl içinde hastane yatışı varsa $B N P \geq 100 \mathrm{pg} / \mathrm{ml}$ veya NT-proBNP $\geq 400 \mathrm{pg} / \mathrm{ml}$.

men primer sonlanım noktasına (kardiyovasküler ölüm veya KY nedenli yatış) ulaşılmıştır. Bu da iyi tedavi alan görece stabil hastaların da hala ciddi klinik sonuçlar açısından yüksek riskli olduğunu göstermektedir. Klinik olarak S/V etkinliği bu stabil grupta gözlenmiştir. Enaprile göre $S / V$ 'nın üstünlüğü hastaların demografik ve klinik özelliklerinden bağımsız olarak bütün alt gruplarda gözlenmiştir. ${ }^{[6]}$ Birleşik Devletlerde yapılan bir analizde toplumda ACEİ/ARB'yi tolere eden NYHA II-III DEFKY hastalarına uygulanacak S/V tedavisi ile yıllık yaklaşık 28000 ölümün engellenebileceği gösterilmiştir. ${ }^{[8]}$

PARADIGM-HF çalışmasının bu kayda değer sonuçları sonrasında DEFKY hastalarında S/V kullanımı Avrupa ve Amerika KY kılavuzlarında yer bulmuştur. 2017 yılı ACC/AHA/HFSA kılavuz güncellemesinde S/V kullanımı DEFKY hastarında mortalite morbiditenin azaltılması açısından SINIF IB düzeyinde önerilmektedir, ayrıca kronik semptomatik NYHA II-III DEFKY hastalarında ACEI/ARB'nin S/V ile değiştirilmesini de yine sınıf IB düzeyinde tavsiye etmektedir. 2016 ESC KY k1lavuzunda ise S/V tolere edilebilen maksimum dozda ACEİ/ARB, beta-bloker ve MRA kullanan NYHA II-IV hastalarda sinıf IB düzeyinde önerilmektedir. Her iki kılavuz kuvvetle S/V kullanımını önermekle birlikte ilacın başlanma zamanı ve başlanma kriterleri açısından bazı farklılıklar da içermektedir. Her iki kılavuzda da, PARADIGM-HF çalışmasında olduğu gibi, ARNİ başlanması öncesinde mutlaka ACEI/ARB kullanılmasını istemektedir. Ancak, ESC kılavuzu ACEİ/ARB, beta-bloker ve MRA kullanımına rağmen semptomatik hastalarda ACEİ yerine ARNİ başlanmasını önerirken, ACC/ AHA kılavuzu ACEİ veya ARB'yi tolere edebilen ve yakınmaları süren hastalarda ARNI'ye geçilebileceğini söylemektedir. ACC/AHA k1lavuzunda ARNİ'ye geçilmeden önce MRA kullanım şartı bulunmamaktadır. Her iki kılavuz arasında ARNİ başlama kriterleri açısından da bazı farklılıklar bulunmaktadır. ESC KY kılavuzu ARNİ başlanması için EF'nin \%35 ve altında olmasinı isterken, ACC/AHA kılavuzu kesin EF sinırı belirtmemekte, genel olarak DEF-KY'de kullanılabileceğini ifade etmektedir. ESC KY kılavuzu ARNİ başlanması için NYHA II-IV koşulunu ararken, ACC/AHA kılavuzu NYHA II-III koşulunu getirmektedir. ESC kılavuzu, ARNI başlanabilmesi için BNP $\geq 150 \mathrm{pg} / \mathrm{ml}$ veya NT-proBNP $\geq 600 \mathrm{pg} / \mathrm{mL}$ olmas1$\mathrm{n}$ ı veya hasta bir yıl içinde hastanede yatmışsa BNP $\geq 100 \mathrm{pg} / \mathrm{ml}$ veya NT-proBNP $\geq 400 \mathrm{pg} / \mathrm{mL}$ olmasi şartını aramaktadır. ACC/AHA kılavuzunda ise natriüretik peptid şart1 yoktur. ESC kılavuzunda ARNI öncesi enalapril 2x10 mg kullanımına eşdeğer bir ACEİ/ARB kullanım şartı aranırken, ACC/AHA kılavuzunda ACEİ veya ARB'yi tolere edebilen olgularda kullanılabileceği önerilmekte, bir ACEİ/ ARB doz kullanım şartı aranmamaktadır (Tablo 1). Ülkemizde ekim 2015 yılında yayınlanan Kronik Kalp Yetersizliğinde Pratik Yaklaşımlar Rehberinde S/V başlama önerisi olarak ACEİ ve beta-bloker kullanımına rağmen semptomatik NYHA Sınıf II-IV ve EF'si \%40'ın altında olan olgularda MRA veya ARNI'ye geçilebileceği ifade edilmiştir. ${ }^{[9]}$

Sonuç olarak DEFKY tedavisi ve yönetimi son yıllarda önemli oranda ilerleme sağlamasına rağmen mortalite oranları hala yüksek kalmaya devam etmektedir ve ne yazık ki hastaların sadece $\% 50$ 'si tanıdan sonra 5 yıldan fazla yaşamaktadır. ${ }^{[10]}$ PARADIGM-HF çalışmasından elde edilen veriler, görece 'stabil' kronik KY hastalarının asemptomatik KY ilerleyişi, ölüm ve hastaneye yatış gibi risklerinin halen yüksek olduğunu ve S/V ile stabil NYHA II-III olgularında enalaprile göre anlamlı daha fazla klinik yarar sağlandığını göstermektedir. Bu sonuçlar stabil seyreden NYHA II KY olgularında ACEİ'den S/V'ye geçilmesinin mantıklı bir yaklaşım olacağını desteklemektedir.

\section{Kaynaklar}

1. Ponikowski P, Voors AA, Anker SD, Bueno H, Cleland JG, Coats AJ, et al. 2016 ESC Guidelines for the diagnosis and treatment of acute and chronic heart failure: The Task Force for the diagnosis and treatment of acute and chronic heart failure of the European Society of Cardiology (ESC). Developed with the special contribution of the Heart Failure Association (HFA) of the ESC. Eur J Heart Fail 2016;18:891-975.

2. Ammar KA, Jacobsen SJ, Mahoney DW, Kors JA, Redfield MM, Burnett JC Jr, et al. Prevalence and prognostic significance of heart failure stages: application of the American College of Cardiology/ American Heart Association heart failure staging criteria in the com- 
munity. Circulation 2007;115:1563-70.

3. Carson P, Anand I, O'Connor C, Jaski B, Steinberg J, Lwin A, et al. Mode of death in advanced heart failure: the Comparison of Medical, Pacing, and Defibrillation Therapies in Heart Failure (COMPANION) trial. J Am Coll Cardiol 2005;46:2329-34.

4. Latini R, Masson S, Anand IS, Missov E, Carlson M, Vago T, et al. Prognostic value of very low plasma concentrations of troponin $\mathrm{T}$ in patients with stable chronic heart failure. Circulation 2007;116:12429.

5. Yancy CW, Jessup M, Bozkurt B, Butler J, Casey DE Jr, Colvin MM, et al. 2017 ACC/AHA/HFSA Focused Update of the 2013 ACCF/ AHA Guideline for the Management of Heart Failure: A Report of the American College of Cardiology/American Heart Association Task Force on Clinical Practice Guidelines and the Heart Failure Society of America. J Card Fail 2017;23:628-51.

6. McMurray JJ, Packer M, Desai AS, Gong J, Lefkowitz MP, Rizkala AR, et al. Angiotensin-neprilysin inhibition versus enalapril in heart failure. N Engl J Med 2014;371:993-1004.

7. Desai AS, McMurray JJ, Packer M, Swedberg K, Rouleau JL, Chen F, et al. Effect of the angiotensin-receptor-neprilysin inhibitor LCZ696 compared with enalapril on mode of death in heart failure patients. Eur Heart J 2015;36:1990-7.

8. Fonarow GC, Hernandez AF, Solomon SD, Yancy CW. Potential Mortality Reduction With Optimal Implementation of Angiotensin Receptor Neprilysin Inhibitor Therapy in Heart Failure. JAMA Cardiol 2016;1:714-7.

9. Çavuşoğlu Y, Altay H, Ekmekçi A, Eren M, Küçükoğlu MS, Nalbantgil S, et al. Practical approaches for the treatment of chronic heart failure: Frequently asked questions, overlooked points and controversial issues in current clinical practice. Anatol J Cardiol 2015;15:1-60.

10. Mozaffarian D, Benjamin EJ, Go AS, Arnett DK, Blaha MJ, Cushman M, et al. Heart disease and stroke statistics--2015 update: a report from the American Heart Association. Circulation 2015;131:e29322. 